\title{
Historical Perspective of the WIC Program and Its Breastfeeding Promotion and Support Efforts
}

The Special Supplemental Nutrition Program for Women, Infants, and Children (WIC) was established in 1972 by an amendment to the 1966 Child Nutrition Act, and became a permanent program in $1974 .^{1}$ Administered federally by the US Department of Agriculture (USDA) Food and Nutrition Service and typically managed by state health departments, WIC participation greatly expanded since its inception. The program is well recognized as an adjunct to health care during critical times of growth and development and is considered an entry point to other health and social services for low-income families. ${ }^{2-4}$ It serves nutritionally at-risk pregnant, breastfeeding (BF), and postpartum women, infants, and children age $<5$ years, providing supplemental nutritious food and nutrition education as well as referrals to social and health services. ${ }^{1}$ Collective findings of studies, reviews, and reports demonstrated that WIC is cost-effective in protecting and improving the health and nutritional status of participants. ${ }^{5-9}$ The required nutrition education component is the benefit that sets WIC apart from other federal nutrition assistance programs.

Historically, WIC included BF promotion and support as part of its supplemental food and nutrition education programming efforts. BF provides multiple health, nutritional, economical, and emotional benefits to mothers and babies. ${ }^{10}$ This led to both the issuance in 2011 of the Surgeon General's Call to Action to Support Breastfeeding $^{10}$ and the establishment of Healthy People 2020 BF goals. ${ }^{11} \mathrm{Hu}-$ man milk is considered the best source of infant nutrition that also offers immunological and anti-inflammatory properties to protect infants from ear, respiratory, and gastrointestinal infections as well as other health issues. ${ }^{12-18}$ Furthermore, BF protects mothers against diseases such as breast and ovarian cancer, type 2 diabetes, and obesity, and postpartum depression. ${ }^{19}$
The US Department of Health and Human Service's Centers for Disease Control and Prevention collects BF data using the US National Immunization Survey. ${ }^{20}$ Table 1 lists the $2016 \mathrm{Na}$ tional Immunization Survey data, ${ }^{21}$ which indicate that the nation and WIC mothers fell short of the 2020 Healthy People BF goals. However, data from the 2014 WIC Participant and Program Characteristics Report 2014 showed a steady increase in WIC BF initiation rates from $48.3 \%$ in 2002 to $68.9 \%$ in 2014, indicating that more mothers chose BF as their first choice for infant feeding. Despite all known benefits, mothers enrolled in WIC continue to face multiple barriers in reaching their BF goals. ${ }^{22,23}$ The Social Ecological Model ${ }^{24,25}$ is used to illustrate the intrapersonal, interpersonal, community, and institutional levels intricately involved in successful BF. Human milk is the normative standard for infant feeding and nutrition ${ }^{26}$ and given that about one half of all US-born infants are enrolled in WIC, the USDA is committed to strengthening efforts to promote and support BF for improved health outcomes. This commentary highlights USDA past national WIC BF activities and reflects on future efforts in BF promotion and support to safeguard the health of all infants and their mothers.

\section{PAST WIC BF PROMOTION EFFORTS}

Since 1990, the USDA has promoted and supported BF in WIC through a number of legislative and programmatic initiatives. ${ }^{27}$ In 1990, the Breastfeeding Promotion Consortium was established to promote the $\mathrm{BF}$ campaign at local and state levels. ${ }^{28}$ This consortium is still active and includes about 25 members from health professional, government, public health, and advocacy organizations. The Breastfeeding Promotion Consortium collaboratively promotes $\mathrm{BF}$ as the normative standard of infant nutrition and child development; works toward achieving the Healthy People 2020 BF objectives, ${ }^{11}$ and supports $\mathrm{BF}$ as a priority for the general public.

The Homeless Children Nutrition Improvement Act of $1992^{27}$ required the USDA to establish a national BF promotion program and foster wider public acceptance of BF in the US. Furthermore, this legislation authorized an enhanced food package to meet the special health and nutritional needs of exclusively lactating women. This food package provided increased amount of juice, cheese, and dry beans and added carrots and tuna as new food items to promote and support BF mothers. ${ }^{29}$ Over the ensuing years, the USDA enhanced efforts to improve $\mathrm{BF}$ initiation and duration rates by providing WIC agencies with guidance and technical assistance to promote and support BF. These efforts were built on the successes of Loving Support Makes Breastfeeding Work (Loving Support), the USDA's national BF promotion and support campaign. ${ }^{30}$ The Loving Support campaign is based on a social marketing approach, emphasizing the concept of the Social Ecological Model that the support of family and friends, the health care system, and the community are all essential for a mother to breastfeed successfully.

\section{DEVELOPMENT OF THE USDA NATIONAL BF CAMPAIGN}

In 1995, the USDA entered into a cooperative agreement with Best Start Social Marketing, Inc. (Best Start, Inc.) to develop and implement a national WIC BF promotion campaign. Social Marketing Theory ${ }^{30}$ guided the design and implementation to meet original campaign goals, which included (1) increasing BF initiation and duration rates among WIC participants, (2) 
Table 1. Breastfeeding Rates by Sociodemographics Among Children Born in $2013(\%)$

\section{Healthy People 2020 Goals}

Ever breastfed (82)

Breastfed at 6 mo (61)

Breastfed at $12 \mathrm{mo}(34)$

Exclusive until 3 mo (46)

Exclusive at 6 mo (26)

\section{Total \\ Population}

81

52

31

44

22
Special Supplemental Nutrition Program for Women, Infants, and Children
74
39
21
34
16

increasing referrals to WIC for BF support, (3) increasing general public acceptance and support of BF, and (4) enhancing the potential for sustaining organizational cultural change through technical assistance for WIC state and local agency staff. These goals were addressed through various critical components including consumer research, an extensive media campaign, a staff support kit, a BF resource guide, a community organizer's kit, a staff training conference, and continuing education and technical assistance.

During the project's implementation in 10 pilot WIC state agencies, Best Start, Inc conducted formative research with pregnant women, current $\mathrm{BF}$ mothers, and those who stopped BF at 6 weeks; family members; WIC staff; and health care providers. Findings reflected the impact of WIC on BF promotion and public awareness while identifying barriers to BF such as lack of support and time. $^{30}$ Project findings including feedback from WIC participants and staff were crucial in concept development for the media and social marketing messages. Multiple themes and slogans were tested among WIC participants and staff in focus groups, which resulted in the appeal of the Loving Support concept to the majority of respondents. ${ }^{30}$ Moreover, this concept highlighted the role of a support network from family, friends, and health professionals in reinforcing mothers' BF decisions. With the USDA providing the policy support, this campaign captured elements of Social Ecological Theory to reinforce positive BF behaviors at all levels to foster healthy and well-nourished communities.

Best Start, Inc provided technical assistance to pilot agencies to develop a comprehensive array of resources for participant education, WIC staff training, public awareness, kits for health providers, and promotional items. The campaign was widely embraced, with WIC state and local agencies adopting and promoting a BF-friendly environment and using the various visual education materials, training, billboards, partner kits, and television and radio spots. ${ }^{30}$ As a result of pilot testing, some educational resources were revised to reflect ethnic and cultural diversity in WIC.

During the 1997 celebration of World Breastfeeding Week, the Secretary of Agriculture officially launched the Loving Support campaign. After the launch, the rates of BF initiation in WIC increased steadily from $41.5 \%$ in 1998 to $69.8 \%$ in 2014 . $^{31}$ Furthermore, the 2013 WIC Infant and Toddler Feeding Practices Study 2 showed a positive shift in perceived benefits and beliefs about BF among WIC participants and more WIC mothers believed that BF was the best choice for infant feeding. ${ }^{32}$ In addition, an evaluation of Mississippi's Loving Support outreach and educational activities showed a positive impact on WIC coordinators' as well as health care providers' awareness of the campaign. ${ }^{33}$ Lessons learned from the Loving Support campaign indicated that social marketing programs are effective in promoting and supporting BF behavior change in populations with diverse social and cultural backgrounds. ${ }^{34}$

\section{EXPANSION OF WIC BF ACTIVITIES BEYOND LOVING SUPPORT}

The Loving Support campaign was designed as a continuing, flexible initia- tive implemented at the state agency level. Materials developed during the initial launch as well as subsequent projects (eg, staff training resources and participant educational materials) continued to meet campaign goals (Table 2). ${ }^{35}$

The USDA continued to strengthen its emphasis on and support for BF with targeted funding for new projects. A notable example is the Child Nutrition and WIC Reauthorization Act of 2004, ${ }^{27}$ which provided funds to establish and support BF peer counseling activities to reflect research that demonstrates the significance of these programs in improving BF initiation and duration rates. ${ }^{36-38}$ A majority of WIC state agencies support and integrate peer counseling programs as a core component of WIC services. ${ }^{38}$ The WIC BF peer counselors provide a valuable service to their communities, addressing barriers to BF by offering BF education, support, and role modeling. In fiscal year 2014, the WIC Breastfeeding Policy Inventory showed that $93 \%$ of state agencies reported operating or overseeing local agencies that had peer counseling programs. $^{38}$ In addition, the Healthy, Hunger-Free Kids Act $2010^{27}$ emphasized the importance of BF promotion and support by establishing awards for exemplary BF practices at the local level, increasing funding for peer counseling programs, and implementing a state BF performance bonus.

\section{THE USDA NATIONAL BF CAMPAIGN: A WAY FORWARD}

In 2011, the USDA requested that the Institute of Medicine of the National Academies convene an expert panel workshop to discuss current and future updates of the Loving Support campaign to meet changing needs of WIC participants. The Institute of Medicine workshop summary report provided guidance on evidencebased and social marketing best practices relevant to informing a new BF campaign. ${ }^{39}$ In 2014, the Food and Nutrition Service awarded a 3-year cooperative agreement to Hager Sharp, Inc, a health communications firm, to update the existing USDA BF promotion campaign based on a comprehensive social marketing plan 
Table 2. WIC Program Breastfeeding Promotion and Support Efforts

\begin{tabular}{|c|c|c|}
\hline Year & Name & Description \\
\hline 2002 & $\begin{array}{l}\text { Using Loving Support to Build a Breastfeeding-Friendly } \\
\text { Community }\end{array}$ & $\begin{array}{l}\text { Training and technical support to assist WIC state } \\
\text { agencies in building comprehensive community-based } \\
\text { BF partnerships }\end{array}$ \\
\hline 2002 & Fathers Supporting Breastfeeding & $\begin{array}{l}\text { Resource to increase BF initiation and duration rates } \\
\text { among African American women by involving fathers }\end{array}$ \\
\hline 2004 & Best Practices in Peer Counseling & $\begin{array}{l}\text { Training to assist WIC state and local agencies in } \\
\text { implementing and enhancing peer counseling } \\
\text { programs }\end{array}$ \\
\hline 2008 & Breastfeeding: a Magical Bond of Love & $\begin{array}{l}\text { Tools to communicate loving connection between a BF } \\
\text { mother, her baby, and other family members for the } \\
\text { Hispanic community enrolled in WIC }\end{array}$ \\
\hline 2009 & Grow and Glow in WIC & $\begin{array}{l}\text { Standardized competency-based BF training curriculum } \\
\text { for all WIC staff }\end{array}$ \\
\hline 2011 & Loving Support Through Peer Counseling & $\begin{array}{l}\text { For training WIC peer counselors: updated training to } \\
\text { provide basic BF information for mother-to-mother } \\
\text { peer support }\end{array}$ \\
\hline 2016 & Loving Support Through Peer Counseling & $\begin{array}{l}\text { For WIC managers: updated training on fundamental } \\
\text { aspects of managing peer counseling programs }\end{array}$ \\
\hline
\end{tabular}

BF indicates breastfeeding; WIC, Special Supplemental Nutrition Program for Women, Infants, and Children.

with an emphasis on formative research, appropriately framed educational messages, innovative campaign strategies, and evidence-based promotional materials. The overall intent of the campaign update was to build on successes of the existing Loving Support campaign to inform, motivate, and persuade the audience effectively to increase BF rates among WIC participants and increase support for $\mathrm{BF}$ among those who most influenced BF mothers. In 2015, a project was launched to update and develop WIC BF and training curricula for various levels of WIC staff to develop skills and knowledge further. In addition to BF promotion, support, and counseling, the WIC food package provided more benefits to BF mothers and infants. BF mothers are also eligible to participate in WIC longer than are non- BF mothers. ${ }^{40,41}$

\section{IMPLICATIONS FOR RESEARCH AND PRACTICE}

It is well established that human milk is the normative standard for infant feeding and health and that the role of socially and culturally relevant peer counseling is effective in reinforcing $\mathrm{BF}$ behaviors including exclusivity. ${ }^{42-44}$ However, improving BF rates is a complex issue that requires a myriad of continuous and consistent educational and support mechanisms for mothers to succeed in meeting their BF goals. The authorizing legislation for $\mathrm{WIC}^{45}$ provides a strong basis for WIC's role in BF promotion and support. Policy guidance on WIC $\mathrm{BF}$ and the food package support WIC agencies in strengthening their policies and procedures to ensure BF mothers receive a food package consistent with their increased nutritional needs and those of their infants, and that BF support and assistance are provided throughout the prenatal and postpartum periods. ${ }^{46}$ Evidencebased trainings using the Loving Support model increase skills and knowledge for all WIC staff. Such trainings are ongoing to emphasize staff responsibilities for BF promotion, support, and assessment; issuance of appropriate food packages; maintenance of BF-friendly clinics; and operation of effective peer counseling programs. Collaborations with key stakeholders and community partners could allow WIC to expand referral networks that build BF-friendly communities that support the continuum of care during the prenatal and postpartum periods. With great strides made in BF promotion and support, the USDA remains committed to these activities and will continue to use research to inform future efforts to promote and support BF in WIC, assist mothers enrolled in WIC to reach their BF goals, and contribute to achieving the Healthy People 2020 BF goals.

\section{ACKNOWLEDGMENTS}

Funding for this Commentary was provided by the USDA-Food and Nutrition Service. The authors gratefully acknowledge all contributors and the Food and Nutrition Service staff who provided technical editing and reviews to the manuscript.

Anne Bartholomew, MS, RD* Pascasie Adedze, PhD, MPH Valery Soto, MS, RD, CLC Cheryl Funanich, MEd, RD, LD Terra Newman, MPH, RD Patricia MacNeil, MS

US Department of Agriculture-Food and Nutrition Service, Alexandria, VA

*Address for correspondence: Anne Bartholomew, MS, RD, Nutrition Service Branch, US Department of AgricultureFood and Nutrition Service, 3101 Park Center Dr, Rm 520, Alexandria VA 22302; Phone: (703) 305-2746; Fax: 703-305-2196

E-mail: anne.bartholomew@fns.usda. 


\section{REFERENCES}

1. US Department of Agriculture, Special Supplemental Nutrition Program for Women, Infants and Children (WIC). https:// www. fns.usda.gov/wic/about-wic-wicsmission. Accessed October 1, 2016.

2. Foster EM, Jiang M, GibsonDavis CM. The effect of the WIC program on the health of newborns. Health Services Res. 2010;45:1083-1104.

3. Khanani I, Elam J, Hearn R, Jones C, Maseru N. The impact of prenatal WIC participation on infant mortality and racial disparities. Am J Public Health. 2010;100(supp11):S204-S209.

4. Richards R, Merrill RM, Baksh L, McGarry J. Maternal health behaviors and infant health outcomes among homeless mothers: U.S. Special Supplemental Nutrition Program for Women, Infants, and Children (WIC) 2000-2007. Prev Med. 2011;52:87-94.

5. Edmunds LS, Sekhobo JP, Dennison BA, Chiasson MA, Stratton $\mathrm{HH}$, Davison KK. Association of prenatal participation in a public health nutrition program with healthy infant weight gain. Am J Public Health. 2014;104(suppl 1):S35-S42.

6. Jackson MI. Early childhood WIC participation, cognitive development and academic achievement. Soc Sci Med. 2015;126:145-153.

7. Bitler MP, Currie J. Does WIC work? The effects of WIC on pregnancy and birth outcomes. J Policy Anal Manage. 2005;24:73-91.

8. Kowaleski-Jones L, Duncan GJ. Effects of participation in the WIC program on birthweight: evidence from the $\mathrm{Na}$ tional Longitudinal Survey of Youth. Am J Public Health. 2002;92:799-804.

9. Oliveira V, Frazao E. The WIC Program: Background, Trends, and Economic Issues. Report No. 73. Washington, DC: USDA-Economic Research Service; 2009.

10. US Department of Health and Human Services. The Surgeon General's Call to Action to Support Breastfeeding. Washington, DC: US Dept of Health and Human Services, Office of Surgeon General; 2011.

11. US Department of Health and Human Services, Office of Disease Prevention and Health Promotion. Healthy People 2020. https://www.healthypeople.gov/ 2020/topics-objectives/topic/maternalinfant-and-child-health/objectives. Accessed October 1, 2016.
12. American Academy of Pediatrics Committee on Nutrition. Feeding the infant. In: Kleinman RE, Greer FR, eds. Pediatric Nutrition. 7th ed. Elk Grove Village, IL: American Academy of Pediatrics; 2014:15-134.

13. Sankar MJ, Sinha B, Chowdhury R, et al. Optimal breastfeeding practices and infant and child mortality: a systematic review and meta-analysis. Acta Paediatr. 2015;104:3-13.

14. Bowatte G, Tham R, Allen K, et al. Breastfeeding and childhood acute otitis media: a systematic review and meta-analysis. Acta Paediatr. 2015;104: 85-95.

15. Duijts L, Ramadhani MK, Moll HA. Breastfeeding protects against infectious diseases during infancy in industrialized countries: a systematic review. Matern Child Nutr. 2009;5:199-210.

16. Renfrew MJ, McCormick FM, Wade A, Quinn B, Dowswell T. Support for healthy breastfeeding mothers with healthy term babies. Cochrane Database Syst Rev. 2012;5:CD001141.

17. Kramer MS, Kakuma R. Optimal duration of exclusive breastfeeding. Cochrane Database Syst Rev. 2012;8: CD003517.

18. Academy of Nutrition and Dietetics. Position of the Academy of Nutrition and Dietetics: Promoting and supporting breastfeeding. J Acad Nutr Diet. 2015;115:444-449.

19. Ip S, Chung M, Raman G, et al. Breastfeeding and maternal and infant health outcomes in developed countries: evidence report/technology assessment. AHRQ Pub No. 07-E007. Agency of Healthcare Research and Quality: Rockville, MD; 2007;153:1-186.

20. Centers for Disease Control and Prevention-National Immunization Surveys. Breastfeeding Report Card: progressing toward national breastfeeding goals, United States, 2016. https://www.cdc. gov/breastfeeding/pdf/2016breastfeedin greportcard.pdf. Accessed December 20, 2016.

21. Centers for Disease Control and Prevention-National Immunization Surveys. Rates of any and exclusive breastfeeding by socio-demographics among children born in 2013. https:// www.cdc.gov/breastfeeding/data/nis_ data/rates-any-exclusive-bf-socio-dem2013.htm. Accessed December 20, 2016.

22. Hedberg IC. Barriers to breastfeeding in the WIC population. Am J Matern Child Nurs. 2013;38:244-249.
23. Donath SM, Amir LH: ALSPAC Study Team. Relationship between prenatal infant feeding intention and initiation and duration of breastfeeding: a cohort study. Acta Paediatr. 2003;92: 352-356.

24. Dunn RL, Kalich KA, Fedrizzi R, Phillips S. Barriers and contributors to breastfeeding in WIC mothers: a social ecological perspective. Breastfeed Med. 2015;10:493-501.

25. Contento IR. Nutrition Education: Linking Research, Theory, and Practice. 2nd ed. Burlington, MA: Jones \& Bartlett Learning; 2011.

26. American Academy of Pediatrics Policy Statement: breastfeeding and the use of human milk. Pediatrics. 2012; 129:e827-e841.

27. US Department of Agriculture. Legislative history of breastfeeding promotion requirements in the WIC Program. https://www.fns.usda.gov/sites/default/ files/wic/LEGISLATIVE-HISTORYOF-BF.pdf. Accessed October 1, 2016.

28. US Department of Agriculture. Breastfeeding Promotion Consortium. https://www.fns.usda.gov/wic/breastfee ding-promotion-consortium-bpc. Accessed October 15, 2016.

29. US Department of Agriculture. Special Supplemental Food Program for Women, Infants and Children (WIC); enhanced food package for breastfeeding women. Final Rule. Federal Register (57 FR 56231). Vol. 57(229). November 27, 1992.

30. Best Start Social Marketing, Inc. Loving Support Makes Breastfeeding Work. Alexandria, VA: Final report submitted to USDA-Food and Nutrition Service, Supplemental Food Programs Division, WIC; 1999.

31. Thorn B, Tadler C, Huret N, et al. WIC participant and program characteristics 2014. Prepared by Insight Policy Research for USDA-FNS, Alexandria, VA. http://www.fns.usda. gov/sites/default/files/ops/WICPC2014. pdf. Accessed October 15, 2016.

32. May L, Borger C, McNutt S, et al. WIC infant and toddler feeding practices study 2: intention to breastfeed. Prepared by Westat for USDA-FNS, Alexandria, VA. http://www.fns.usda.gov/sites/default/ files/ops/WICITFPS2-Prenatal.pdf. Accessed November 1, 2016.

33. Mitra AK, Khoury AJ, Carothers C, Foretich C. Evaluation of a comprehensive Loving Support program among State Women, Infants, and Children (WIC) 
program breastfeeding coordinators. South Med J. 2003;96:168-171.

34. Perez-Escamilla R. Breastfeeding social marketing: lessons learned from USDA's Loving Support campaign. Breastfeeding Med. 2012;7:358-363.

35. US Department of Agriculture-Food Nutrition Service. https://lovingsupport. fns.usda.gov/. Accessed October 1, 2016.

36. Gross SM, Resnik AK, Cross-Barnet C, Nanda JP, Augustyn M, Paige DM. The differential impact of WIC peer counseling programs on breastfeeding initiation across the state of Maryland. J Hum Lact. 2009;25:435-443.

37. Epstein C, Collins A, et al. WIC breastfeeding peer counseling study: phase II follow up implementation report. Prepared by Abt Associates for USDAFNS, Alexandria, VA. http://www. fns.usda.gov/sites/default/files/ops/WIC PeerCounseling-PhaseII.pdf. Accessed December 1, 2016.
38. Forrestal S, Briefel R, Mabli J. WIC breastfeeding policy inventory report. Prepared by Mathematica Policy Research for USDA-FNS, Alexandria, VA. https://www.fns.usda.gov/sites/de fault/files/ops/WICBPI.pdf. Accessed December 1, 2016.

39. Institute of Medicine. Updating the USDA national breastfeeding campaign: workshop summary. Washington, DC: National Academies Press; 2011.

40. US Department of Agriculture. Final rule: revisions in the WIC food package. https://www.fns.usda.gov/wic/fin al-rule-revisions-wic-food-packages. Accessed December 1, 2016.

41. Schultz DJ, Shanks CB, Houghtaling B. The impact of the 2009 special supplemental program for women, infants, and children food package revisions on participants: a systematic review. J Acad Nutr Diet. 2015; 115:1832-1846.
42. Chapman DJ, Morel K, Anderson AK, Damio G, Pérez-Escamilla R. Breastfeeding peer counseling: from efficacy through scale-up. J Hum Lact. 2010;26: 314-326.

43. Gross TT, Powell R, Anderson AK, Hall J, Davis M, Hilyard K. WIC peer counselors' perceptions of breastfeeding in African-American women with lower incomes. J Hum Lact. 2015;31:99-110.

44. US Department of Agriculture Service. WIC Loving Support model. www. wicworks.fns.usda.gov/wicworks/Lear ning_Center/FNS_model.pdf. Accessed December 1, 2016.

45. US Department of Agriculture. http:// www.fns.usda.gov/wic/wic-laws-andregulations. Accessed December 1, 2016.

46. US Department of Agriculture. WIC Guidance. http://www.fns.usda.gov/ wic/guidance. Accessed December 1, 2016. 


\section{CONFLICT OF INTEREST}

All authors of this paper are employees of the US Department of Agriculture-Food and Nutrition Service. 